\title{
México: la construcción fallida de un Estado y las nuevas reformas políticas
}

\author{
México: the failed construction of one state and the new political \\ reforms
}

\section{Manuel Ángel Rodríguez Edeza}

\section{Resumen}

El presente ensayo intenta explicar la historia de México. Asume a México como un régimen autoritario, que no ha podido conformar una verdadera democracia y cuya explicación se encuentra en su pasado y prácticas históricas. La tesis que se sostiene, es que México vivió desde su origen en un régimen autoritario o cuasi autoritario, con una estructura vertical, una autoridad vertical y un pueblo vertical; donde lo más que pudo (y ha podido) resolver es su sobrevivencia.

\section{Palabras clave}

México; História; Cultura Histórica; Prácticas Históricas; Autoritarismo.

\section{Abstract}

This essay tries to explain the history of Mexico. It assumes to Mexico like an authoritarian regime, that has not been able to conform a true democracy and whose explanation is in its past and "historical practices". The thesis that is held is that Mexico lived from its origin an authoritarian regime or semi authoritarian, with a vertical structure, a vertical authority and a vertical people; where the most that he has could resolves it is his "survival".

\section{Keywords}

México; History; Historical Culture; Historical Practices; Authoritarianism. 


\section{Introducción}

México ha sido imperio, "protectorado religioso", monarquía, "Estado eclesiástico", dictadura, falsa República y protectorado económico, pero nunca un verdadero Estado democrático. Emanó desde su origen, pre y post colombino de un poder central y centralizado, donde señorearon grandes imperios, incluido el español, por el que fue conquistado. Se desenvolvió después, como un protectorado católico, una monarquía, una república que no alcanzó a ser construida, una dictadura "republicana", un gobierno con características "metaconstitucionales" y, en los últimos decenios, un país supeditado al capital económico internacional, pero nunca ha podido construir su propia historia.

Muchas son las situaciones y derroteros que lo han llevado por este camino, algunas veces circunstanciales y otras ocasionales; pero también las ha habido de intereses personales, acaudilladas y, de grupo, ante un pueblo, que tampoco ha sabido cómo defenderse.

La propuesta del presente ensayo, es hurgar en el pasado la posible explicación de los presentes; la cultura histórica o, los legados del autoritarismo, diría Rodrigo Stumpf González (2015). ¿Por qué México no ha podido dar el salto definitivo? ¿Por qué aún y con todas las luchas, gobiernos, constituciones y reformas, siempre ha sido una nación en vías de desarrollo? ¿Habrá que buscar acaso en otro lado, en otra parte? Nosotros creemos que la historia tiene más cosas que decir que solamente ser la narración de los hechos pasados.

La tesis que se sostiene es que México vivió desde su origen un régimen autoritario (PAZ, 1970), con una estructura vertical, una autoridad vertical y un pueblo vertical; donde lo más que pudo (y ha podido) resolver es su "sobrevivencia".

\section{Antecedentes}

Hacia el año 1500 a. C, se remonta la primera cultura mesoamericana en lo que hoy es México: la Olmeca, cuando todavía Grecia no era la "cuna" de la democracia, ni Roma, la primera República instaurada. De allí en adelante, reyes y gobernantes, dioses y deidades, se fundirán y confundirán en un solo hombre-Dios, o Dios-hombre, Guerrero o Rey o gobernante supremo enviado por los dioses (PAZ, 1970), será la característica más predominante de la cultura y/o culturas que poblarán a la nación mexicana. La última, la mexica, que dominaba los territorios mesoamericanos a la llegada de los españoles. 


\section{La conquista}

La conquista de México fue uno de los encuentros más misteriosos en la historia humana, señala Enrique Krauze (1997). "Sus significados profundos, sus implicaciones culturales y hasta teológicas, escapan todavía nuestra comprensión" (KRAUZE, 1997, p. 44). Yo diría a nuestro entendimiento. Lo cierto es que la tierra conquistada es presa de sus ritos, de sus miedos e idolatrías y, el retorno de su Dios "Cortés-Quezatlcoatl”, Dios ausente, jefe, sacerdote, es para retomar sus tierras y un reino suyo, desde tiempos inmemoriales (PAZ, 1970).Pero por otro lado, está la Corona español; también religiosa, también imperial, ávida de comercio, oro y plata, que habrá de tomar a la tierra descubierta, no producto de una guerra(aunque las hubo), sino de su llegada circunstancial a las indias ${ }^{1}$, de cualquier modo, la suerte de la nueva nación (y de las nuevas naciones) estaba echada.

Desde mediados del siglo $\mathrm{XV}$, se buscaban regiones para comercializar, particularmente por parte de los portugueses en algunas islas de las costas de África, India y Sudeste Asiático debido a la demanda que se venía produciendo en parte de Europa de especias y sedas; las islas se necesitaban además, porque buscaban la siembra de caña de azúcar; esto se hizo mucho más fácil porque muchas de ellas estaban deshabitadas, el trabajo duro lo hacían los esclavos que llegaban a encontrar y capturar y, a veces los compraban (CRESPO, 2009). Al ver que estas actividades estaban siendo muy bien remuneradas, los españoles copiaron el modus operandi de los portugueses, el cual desarrollaron en las islas canarias. Por este motivo creció el deseo de los reyes de castilla de financiar el viaje de Cristóbal Colón en 1492.

Para México, la conquista tuvo su origen en Cuba en 1517, en la que los españoles tenían aproximadamente 20 años de haber llegado. Francisco Hernández de Córdoba arriba a las costas de Yucatán y, en la tercera expedición en 1519, Hernando Cortés, habrá de fundar el primer ayuntamiento de la Nueva España: la Villa Rica de la Vera Cruz. No obstante, la joya de la corona, se convirtió literalmente, en MéxicoTenochtitlan, que era el imperio mexica, al cual incursionaron a fines de ese mismo año apoyados por los señoríos tlaxcaltecas, enemigos acérrimos en ese momento ya

\footnotetext{
${ }^{1}$ Aquí conviene decir que, ciertamente España estaba intentando reforzar y "ampliar” su poderío católico, toda vez que sufría ya los efectos de una reforma religiosa que precisó posteriormente hasta de una contrarreforma, pero su llegada y "conquista" desde nuestro punto de vista, es más por fines económicos o de comercio que religiosos, aunque a la postre, terminarían siendo estos irónicamente más determinantes en su "imperialización”.
} 
del imperio Azteca y tomaron definitivamente en 1521, con el derrocamiento de Cuauhtémoc, su último emperador.

Pero la época pre-colonial o precolombina, tampoco fue del todo pacífica ni de actitudes democráticas, el poder del monarca (o de los monarcas indios) en su gran mayoría, era un poder político basado en la fuerza, "religión" y/o imposición Los mexicas (o aztecas), junto a otras tribus, como los huastecos, totonacas y tlaxcaltecas, se disputaban el poder político en luchas fratricidas, distinguiéndose por sus festejos antropófagos a la vera de sus triunfos (CRESPO, 2009).

Es decir, desde esta perspectiva, el poder político de los mexicas primero y, luego el poder o interés económico (y religioso) de los conquistadores, fincaron los orígenes (que no las bases), de lo que hoy es México. Aunque ciertamente no va a ser lo primero sino lo segundo que comienza la historia de la nueva nación. Sin un México conquistado, para bien o para mal, no habría nación mexicana y el futuro de los mexicas o aztecas o se habría perdido en los anales de la historia o seguiría un rumbo distinto al mexicano.

Por lo que habría dos cosas que resaltar hasta aquí, el poder político de ambos, mexicas y españoles es piramidal, o casi unipersonal, lo que de entrada, no implicó mayor trámite de someter o cambiar una estructura gubernamental (cuasimental) propia de la Espańa de la época; por otro lado, las creencias (o religiosidad), van a jugar un papel también central en la conquista; aunque ciertamente los originarios adoraban otros dioses, y no fue fácil su transmutación, la estructura psicológica hacia lo sagrado y lo supremo, va a ayudar en mucho su mutación (PAZ, 1970). Por lo demás, la avidez por la riqueza, fundamentalmente el oro y la forma de conseguirlo como tributo de los pueblos más débiles, es otra de las características a tomar en cuenta. Así fue la primera parte de la historia.

\section{La época colonial}

Acabado el periodo de peleas, se realizó un paso muy importante que tenían los militares colonizadores como mandato desde Espańa, que era la de poblar con españoles cada región que conquistaban (GARCÍA, 2004).

Entre 1522 y 1523 , llegaron miles de pobladores, no con el total agrado de los conquistadores, por cierto, quienes se encargaron de crear un poder político en cada centro de población que se fue conquistando, sin faltar obviamente lo económico. Por otro lado, la llegada también de las órdenes religiosas franciscanas, dominicas y agustinas en 1924, amplían las prácticas religiosas, como la misa, los bautismos, el 
culto a los santos y el matrimonio. "Entre 1530 y 1560 aproximadamente, tuvo lugar lo que podría llamarse la consolidación de la conquista” (GARCÍA, 2004, p. 128).

Por otro lado, los señoríos independientes que apoyaron a los españoles en su conquista, como los ya sometidos, tenían una relación muy dura con éstos, a veces hasta conflictiva, que era difícil llegar a acuerdos, por lo que se estableció un sistema llamado de encomiendas o representantes, que curiosamente su función básica era lo que se hacía con los gobernantes de México-Tenochtitlan y la Triple Alianza ${ }^{2}$, el cobro de tributos, solo que ahora se los pagaban aellos (los españoles), conservándoles el poder político.

Con todo, se podría decir sin embargo que el proceso general se dio en un periodo de paz (GARCÍA, 2004), "en vez de la brutal colisión de dos mundos remotos, extraños y casi irreductibles entre sí, la Nueva España pudo disponer su vida social siguiendo la forma de un triángulo: los intereses materiales (de los españoles) al acoso, los indígenas en la resistencia (pacífica) y la Corona (y su iglesia) como protectora" (KRAUZE, 1997, p. 44).

Para construir al país, hubieron al menos tres proyectos: uno de dominación directa donde las piezas claves seguirían siendo encomenderos, religiosos y caciques; un segundo y opuesto, donde los pobladores españoles demandaban su propio espacio y un gobierno que los representara, pero no el de los encomenderos y, un tercero, el de la Corona, que fue el que triunfó, con un gobierno central fuerte, emanado desde España, que gobernaría a todos, conquistadores y españoles (GARCÍA, 2004).

Con la expansión hacia el norte de la colonia, "la rebeldía" presentada ya contra los encomenderos, que van a ser sustituidos progresivamente por corregidores y alcaldes y, la implantación del Santo Oficio que robusteció un cuerpo eclesiástico controlado por el gobierno, "la Corona logró afianzar su proyecto y su sistema de gobierno entre 1560 y 1610” (GARCÍA, 2004, p. 140).

A la par no obstante, el propio relevo generacional y el avance mismo de la colonia, va a generar un interés político y económico local cada vez más fuerte, que incluye ahora no solo a los propios herederos peninsulares, sino también a los criollos y mestizos, que han nacido ya en su tierra y que no están dispuestos del todo a ser

\footnotetext{
${ }^{2}$ Ultima confederación de estados indígenas ubicados en el valle de México, conformada por MéxicoTenochtitlan de filiación étnica nahua, Texcoco de filiación acolhua y Tlacopan de tradición otomiana.
} 
sometidos; las reformas borbónicas del Siglo XVIII, arrecian el sometimiento de la Corona sobre la nueva nación y configuran un escenario ideal para la independencia. Por su parte, los indios originarios, ayer respetados en sus intereses políticos, han sido orillados a una situación de súbditos, desposeídos los más de ellos (CRESPO, 2009).

\section{La independencia}

La ideología del movimiento de independencia se dividió entre Hidalgo (primero) y Morelos (después), el primero convencido de Fernando VII y el segundo, ya con el objetivo de un país no monárquico e incipientemente republicano (RAMIREZ, 2015).

Entre 1600 y 1800 , va a florecer en el mundo el pensamiento ilustrado; ya muchos mexicanos han nacido en su nueva patria, llamada entonces Nueva España y están siendo influidos por ese pensamiento de vanguardia. Los enconos que van surgiendo con su madre patria, debido al desmesurado cobro del impuesto y las alcabalas ${ }^{3}$, a la par de la imposición legal desde la corte de Madrid, va haciendo mella en una nueva y creciente burguesía.

Por su parte, el clérigo, que ha jugado un papel importante en la catequización de los indios, ve con agravio y hasta compasión la degradación de los desposeídos. Su adoctrinamiento no concuerda con el saqueo sistemático de los colonizadores. Más de 300 clérigos, participaran en los intentos de rebelión en los territorios conquistados (CRESPO, 2009).

Es en este contexto que,

quienes inician la lucha por la independencia van a ser un puñado de criollos, cuyos planes originales consistían en dar un golpe de fuerza inmediato contra los espańoles. Sin embargo, perdida la ventaja que pudo haberles dado la sorpresa (al ser descubiertos), llamaron en su auxilio a mestizos e indios, pero la sociedad criolla -incluida la Iglesiaatemorizada, se unió a los españoles y la lucha se prolongó (MEYER, 1986, p. 2).

Hidalgo, el precursor de la independencia, se inscribía en una antigua tradición de patriotismo criollo común a toda la América española, que en Nueva Espańa databa del siglo XVI y que había tomado un fuerte impulso en la obra de los

\footnotetext{
${ }^{3}$ Impuesto a las transacciones.
} 
jesuitas criollos ilustrados de mediados del siglo XVIII y a quienes los Borbones, celosos de su influencia, habían expulsado de sus dominios en 1767 (KRAUZE, 1994). "Su móvil personal era el mismo que acariciaba la mayoría de los criollos: la independencia con respecto a España” (KRAUZE, 1994, p. 29).

Para reclamar legítimamente el derecho de propiedad política, económica, burocrática y religiosa, señalaba.

Allende, el capitán criollo que lo secundaba, "creía que Guanajuato, una de las principales ciudades mineras de Nueva Espańa, se convertiría nada menos que en la capital del mundo" (KRAUZE, 1994, p. 25).

Había además en Hidalgo, razones menos idealistas: la brutal exacción fiscal por parte de la Corona a las colonias, destinada a financiar la guerra contra Inglaterra (llamada Consolidación de los Vales Reales, decretada en 1804),

no sólo lo había puesto al borde de la ruina en 1807 con el embargo y amenaza de remate sobre las haciendas suyas y de sus familiares (Santa Rosa San Nicolás, parte de Jaripeo), sino que había afectado, hasta el enloquecimiento y la muerte en 1809, a Manuel, su hermano menor (KRAUZE, 1994, p. 25).

El segundo cura clave para la independencia fue José María Morelos, los dos, prefieren tomar las armas teniendo en cuenta que lo hacían por una buena causa, el cambio político y social (CRESPO, 2009).

Sin embargo, cuando la revolución de independencia perdió a Hidalgo en 1811 y a Morelos en 1815, los liderazgos sobrevivientes fueron menores. La propuesta de la Constitución de Apatzingán, bandera de la Independencia y, de Morelos, se enfilaba hacia una república, pero la guerra se alargaba sin posibilidades de victoria. Allí nació la idea de construir una salida de corto plazo. Los liderazgos criollos locales querían una monarquía propia, porque Fernando VII estaba preso y la Corona en España nunca se preocupó por ellos. Por tanto, convencieron al realista Agustín de Iturbide para que se pasara a los independentistas y terminara la guerra. Iturbide se reunió con Guerrero en 1821 y, la revolución de Independencia terminó. Literalmente.

\section{La vida independiente}

Entre 1821 y 1910 , se sucede la vida independiente (dos veces). El acomodo de la nueva nación en el contexto internacional e, internamente, va a generar muchas 
agitaciones. Por parte del exterior EUA le disputa y quita más de la mitad de su territorio. Por si fuera poco, se instala el segundo imperio, con Maximiliano de Habsburgo al mando, con lo cual se ve amenazada la naciente vida independiente.

Conservadores y reformadores ahora (liberales), van a escenificar episodios violentos e inestables, pero a la vez van a defender la patria. Un personaje simbólico, que a su vez combate de un lado y de otro, liberal y conservador, es Antonio López de Santa Anna, once veces Presidente de México, héroe y villano nacional, que ahuyenta a franceses y norteamericanos por igual, a liberales y conservadores, según sea el caso, convirtiéndose en constructor y destructor de la república, artífice por cierto del derrocamiento de Iturbide. No obstante, el triunfador final y "restaurador" va a ser Juárez, "liberal", que acaudillará la Constitución de 1857 y oficializará las leyes para la reforma de la nueva República.

Sin embargo, el hecho que marcó la historia (hasta la fecha), es la pérdida de muchos kilómetros de la nación mexicana ante los Estados Unidos.

Comenzando todo con la guerra emprendida por los norteamericanos contra México en el año de 1846 y concluida en 1848; con el apoyo precisamente de Santa Anna después de haber tratado las tierras como moneda de cambio si le ayudaban a regresar a la silla del poder (CRESPO, 2009).

Habría que decir sin embargo, que el propio Juárez estuvo a punto de hacer lo mismo y ceder a los deseos del gobierno del otrora presidente Buchanan y convertir a México en un protectorado de los Estados Unidos, todo, a cambio del apoyo estadounidense en la pugna con el bando conservador. Sin embargo,

este proyecto expansionista - que llegó a plasmarse formalmente en un tratado - se frustró por varias circunstancias fortuitas, entre ellas el voto del Senado estadounidense en contra del tratado, y su guerra civil, cuyo efecto, en cuanto a México, fue la modificación de las relaciones entre los dos países que propició la 'penetración' económica en vez de la anexión territorial (KRAUZE, 1994, p. 13).

\section{La República "restaurada"}

Cuando la República y el liberalismo triunfaron sobre la intervención y el partido conservador, señala Cosío Villegas (1973), quedó al frente de los destinos nacionales el equipo más experimentado y patriota que México ha tenido en su historia, "sin embargo, no fue capaz de mantenerse unido...y, acabaron por abrir la puerta a la dictadura porfiriana” (COSÍO, 1973, p. 35). 
Hay que decir que los fundadores de la República Mexicana habían admirado desde siempre a los Estados Unidos. La primera Constitución Federal del México independiente, de 1824, se había inspirado básicamente en la norteamericana (KRAUZE, 1994).

Igual ahora la segunda, "El sol, un diario de la época, consideraba a ésta una de las creaciones más perfectas del espíritu... la base en la que descansa el gobierno más sencillo, liberal y feliz de la historia" (KRAUZE, 1994, p. 9).

Pero el país que nacería de un atraso de siglos para construir un régimen de libertades cívicas y bienestar económico perdería décadas en una discordia civil, que a la postre lo conduciría a la bancarrota, el descrédito, la violencia interna, la guerra exterior y el desmembramiento del territorio.

Una de las razones fundamentales de la discordia atañería al lugar histórico de la Iglesia en la nueva nación, "prácticamente absoluto su dominio espiritual sobre los hombres, no lo era menos, contra todas las tendencias modernas del siglo, su dominio temporal. Poseía la quinta parte de la riqueza nacional" (KRAUZE 1994, p. 67). Así, Juárez, acaudilló al país durante la reforma y, también lo hizo durante una guerra decisiva, la de la Intervención Francesa (1862-1867). Esta vez, ayudado por la siguiente generación liberal, compuesta por caudillos militares (el más notable, Porfirio Díaz), salvó del naufragio al país.

De cualquier modo Juárez fue derrotado, no en su intento por mantener el poder (muere siendo presidente por tercera vez), sino por sostenerlo en beneficio de la nación que quería convertir en una República. La llegada de Díaz al poder habrá de cambiar nuevamente los planes.

\section{El porfiriato}

Una vez construida la República, el elemento económico debe restaurarla, el elemento político dará paso entonces a la restauración económica al mando de Porfirio Díaz, quien traerá el "progreso" a la naciente nación (todavía se discute el papel de Díaz de héroe o villano).Antes de llegar al poder, Díaz se mostró como un hombre de patria, valiente y dispuesto a morir por ésta;"no hay que olvidar momentos tan épicos como el negarse dar su voto pro yanqui en ese momento del despojo al presidente dictador Antonio de Santa Anna” (CRESPO, 2009, p. 240 y 241).

Pero al comenzar su era como Presidente, las cosas cambiaron. "Logró consensuar con los liberales y conservadores: pactando una República liberal para 
calmar los ánimos de los primeros y a los conservadores, les ofreció que no tocaría sus interesses" (CRESPO, 2009, p. 243 y 244).

Supo siempre, que su misión era continuar a Juárez (a quien de algún modo había derrotado). "En su fuero interno, lo veneraba más que ningún otro: no con la lira, con los hechos" (KRAUZE, 1994, p. 179). Sus desavenencias habían sido necesarias, naturales. No correspondía decía, a Juárez, pastorear al rebaño mexicano hacia las siguientes estaciones de emancipación: la paz, el orden y el progreso. Correspondía a la nueva generación, que tenía las armas y la fuerza para hacerlo.

La clave de todo el proceso erala reelección. Contra ella, habían peleado Lerdo y Díaz. La Constitución liberal del 57 la había permitido; Díaz la había combatido al grado de modificar el texto constitucional para prohibirla al triunfar en 1877 . Poco después, el texto había sido modificado de nueva cuenta, se prohibía la reelección inmediata. Pero en 1888 se enmendaba de nuevo el tan manoseado artículo, esta vez para permitir la reelección por un periodo. En 1890 de plano, el Congreso se decidió, en efecto, por la prolongación indefinida. Terminando a la par, con ello, la "restauración de la república".

\section{La Revolución}

Así, con todo y el progreso porfiriano, el límite a las libertades pudo más en la balanza. En 1910, Francisco Ignacio Madero, un próspero empresario y comerciante de la estirpe de los Madero en Coahuila, Estado del norte del país, habrá de reclamar su derecho de existir, junto a una clase política joven que se sentía presa y sin esperanzas de sobreponerse.

A la voz de Sufragio Efectivo no Reelección, la propia proclama otrora porfirista, comenzará la Revolución Mexicana el 20 de noviembre de 1910, en la búsqueda de una "verdadera" República democrática y el fin de la dictadura.

No obstante, tal intento durará sólo 15 meses; tras ganar las elecciones, Madero es traicionado y asesinado el 22 de febrero de 1913por su General "encargado de la defensa" de Palacio Nacional, Victoriano Huerta. "México pudo disfrutar del único experimento de democracia plena los quince meses de su gobierno" (KRAUZE, 1997, p.19).

\section{Generales y caudillos}

A la muerte de Madero, entre batallas y algunas traiciones transitaron 6 años más de revolución, hasta la instauración de la nueva Constitución en 1917, que habrá de recoger la demanda social de los desposeídos. "El derecho a la salud, la vivienda y 
la educación se convierten en pilares de la nueva constitución” (KRAUZE, 1997, p. 42) y la llegada de Venustiano Carranza al poder. Sin embargo, lejos está también de consumarse el México definitivo y la paz perpetua, por el contrario, esta segunda vida institucional, generará tantos escollos como las anteriores. La lucha entre caudillos insurrectos y generales de escuela; y a veces combinados, se va a escenificar por todo el territorio.

Las secuelas de la Revolución, parecen florecer después de muertas y los grandes combatientes de antaño, son los combatientes de ahora, ante una revolución que consideran no ha terminado de fructificar y, lo único que ha hecho es poner un punto y coma, pero no punto final. Así sucederá durante los siguientes 12 ańos, que aunque en tiempo parece poco, no lo ha de ser en la convulsión e inestabilidad nacional.

Los jefes militares se reunieron en la convención más famosa de la historia mexicana, la convención de Aguascalientes, en octubre de 1914, la cual tenía como propósito elegir un nuevo gobierno y redirigir el camino del país, proponiendo a Eulalio Gutiérrez.

No obstante, Villa y Zapata, por un lado, y Carranza por otro, desestimaron la elección, desencadenando un enfrentamiento entre Villa y Obregón en 1915 con una victoria clara para este último, dando paso a la abolición del presidente electo en la convención y entregando la presidencia a Venustiano Carranza (KRAUZE, 1997).

Habían pasado así, los momentos de los caudillos de la Revolución: Francisco I. Madero, Emiliano Zapata y Francisco Villa, para dar paso a los nuevos líderes del país, Carranza y Obregón, los dos en la búsqueda de un México civilizado.

Pero mientras que el primero quería que el principal mandatario fuese civil, el segundo quería que fuese un militar, el triunfo nuevamente del segundo sobre su otrora defendido, lo llevó a la silla presidencial.

No obstante, la llegada de Plutarco Elías Calles al poder en 1924, va a cambiar la historia política y moderna de México, convirtiéndose quizá, en el "verdadero caudillo" y generador de "las prácticas democráticas mexicanas", el Maximato (la prolongación de facto del poder, utilizando presidentes a modo). Artífice además, del órgano que lo posibilitaría, el PNR (Partido Nacional Revolucionario), el partido de la Revolución. 


\section{E1 PRI y su presidencia "metaconstitucional"}

"Las dos piezas principales y características del sistema político mexicano son: una Presidencia de la República con facultades de una amplitud excepcional, y un partido político oficial predominante" (COSÍO, 1973, p. 21).

Nadie niega que el Partido Revolucionario Institucional (PRI) sea del Presidente, tanto como que fue su "inspiración" (aunque la fundación formal del PNR, Partido Nacional Revolucionario, origen del PRI, se da cuando Calles ya ha "abandonado" la Presidencia, la intención de un partido nacional, surge con su impulso y orquestación). De hecho, su posterior transformación a PRM (Partido de la Revolución Mexicana) y, finalmente a PRI (Partido Revolucionario Institucional), durante la administración de Cárdenas y Manuel Ávila Camacho, respectivamente, surgieron también por decisión de los presidentes en turno. Lo único meritorio, fue lograr bajo dicha estrategia emancipar o cooptar los descontentos con la participación política institucionalizada y, la paz (COSÍO, 1973), o al menos arroparla bajo la ley o el garrote.

El mecanismo era simple aunque complejo, todos habrían que aceptarse como la familia revolucionaria y, como tales, herederos del partido y sus preceptos revolucionarios así, podías ser considerado (potencialmente)y ser, presidente, gobernador, senador, diputado, presidente municipal, regidor y, hasta síndico o comisario, "el que se mueve, no sale en la foto", diría el líder eterno de la CTM (Confederación de Trabajadores de México), Fidel Velázquez, uno de los brazos sectorizados del partido, que junto a otros, la CNC (Confederación Nacional Campesina), que aglutinaba a campesinos; la CNOP (Confederación Nacional Obrero Popular), que comprendía al sector popular, incluidos profesionistas, transportistas, ganaderos, comerciantes; el FJR (Frente Juvenil Revolucionario), que haría lo propio con los jóvenes y el CIM (Consejo para la Integración de la Mujer), con las mujeres, no había escapatoria.

Junto a ello, un presidente con facultades metaconstitucionales (CARPIZO, 1978), que no solo disponía de los preceptos ya de por sí presidencialistas otorgados por la Constitución, sino de facultades extra-oficiales como cabeza o jefe del partido pudiendo poner y disponer de todos los puestos, incluido su sucesor. "La constitución de 1917 había dado al Presidente facultades visiblemente superiores a la de los otros dos poderes, particularmente al legislativo" (COSÍO, 1973, p. 22).

Así, el autoritarismo de México fue "oficial" (y hasta necesario). O estabas con el Presidente, o estabas contra él. El entramado político no daba para estar fuera de la foto y si lo estabas, sencillamente no salías (Fidel Velázquez). Partidos de oposición 
que nacieron y fueron "aceptados" por el sistema, sencillamente servían para su legalidad, que no para su legitimación, pero sin ningún riesgo de competirle.

Elecciones fueron y vinieron, "soltando" estratégicamente las posiciones que consideraban pertinentes para seguir siendo la dictadura perfecta, diría Vargas Llosa.

Por un sexenio el Presidente gozaba de un poder absoluto. El que entraba, le debía el puesto al que salía. El que salía se iba impune e inmune. Solo una regla debía ser cumplida. No se heredaba a familia carnal o biológica, solo a la "familia revolucionaria (KRAUZE ,1997, p. 66).

\section{La gradual transición}

Ahora se sabe con certeza,

que el sistema nació con Calles, se corporativizó con Cárdenas, se desmilitarizó con Ávila Camacho y, se convirtió en una empresa con Alemán. (De ahí), el empresario la dejó al contador, Ruiz Cortines, que la cedió al gerente de relaciones públicas, López Mateos, que a su vez la pasó al abogado penal, Díaz Ordaz (KRAUZE, 1997, p. 6).

Dadas las amplísimas facultades legales y extra-legales del Presidente de la República y, dado también el abrumador predominio del partido político oficial, apenas se podía exagerar si se afirmaba que el problema político más importante y urgente de México era contener y aun reducir ese poder excesivo, señalaba Cosío Villegas en 1973. "Sólo los dirigentes del partido no han advertido que grandes grupos de la ciudadanía, ante todo los que no son miembros del PRI, pero también quienes lo son de un modo pasivo, están profundamente insatisfechos" (COSÍO, 1973, p. 80).

El proyecto de artículo 89 enviado al Congreso Constituyente y aprobado en la Constitución de 1917, consagraba al presidente de los Estados Unidos Mexicanos como jefe de Estado, de la administración pública y del ejército, al mismo tiempo que le otorgaba la facultad de veto sobre las leyes aprobadas por el Congreso (CASANOVA, 2008, p. 53).

De este modo, en torno a esas dos instituciones políticas, la presidencia y el partido de la revolución, dentro de un esquema de funcionalidad corporativa se 
desarrollaron las demás instituciones del sistema político mexicano. "El presidente gobernaba, era el jefe del Estado, el jefe militar, el rector de la economía y el otorgador de todos los cargos, tanto de la administración pública como de elección popular" (CASANOVA, 2008, p. 54).

Así se dio el juego a la democracia; instituciones creadas exprofeso y oposición controlada. Sin embargo, el 2 de Octubre de 1968, por un hecho accidental y aislado, se habrá de iniciar la construcción de "otro" México.

\section{El movimiento estudiantil de 1968 y las reformas de 1972 y 1977}

El pleito entre dos grupos estudiantiles va a ser aplacado por el uso de fuerza militar y éstos, unidos, habrán de enfrentar al aparato "opresor".

El Presidente, temiendo que se le salieran de control los acontecimientos en la antesala de la gesta olímpica a celebrarse por primera vez en el país, ordena "todo el peso de la ley" y muchos estudiantes son masacrados impunemente la tarde del 2 de octubre de 1968.

Pero el mundo había cambiado y, las miradas puestas sobre México, van a inspirar un golpe de timón, un cambio de vía. Político, en este caso.

Por si fuera poco, en junio de 1971, la historia se volvió a repetir y, decenas de estudiantes fueron masacrados en el llamado jueves de corpus cristi o "halconazo del 71".

Así, la presión política nacional e internacional, aunada a la crisis económica de 1976, va a producir en 1972 y 1977, las primeras reformas electorales. No obstante, lejos de abrir la llave democrática.

Se elaboró la Ley Federal de Organizaciones Políticas y Procesos Electorales (LFOPPE) que introdujo cambios en el funcionamiento del sistema electoral. Se asignaron atribuciones a la Comisión Federal Electoral (CFE), máximo organismo electoral colegiado y que antes estaban en manos directas de la Secretaría de Gobernación, como el otorgamiento o la cancelación del registro legal de los partidos.

El artículo 41 constitucional estableció la figura de los partidos políticos como "entidades de interés público", definiendo tres prerrogativas fundamentales para su desarrollo: el derecho al uso permanente de los medios de comunicación; el derecho a contar en forma equitativa, con un mínimo de elementos para llevar a cabo sus actividades y, el derecho a participar en las elecciones estatales y municipales.

Se introdujo además, la figura del "registro condicionado", que permitió la obtención del registro legal a los partidos que acreditaran al menos cuatro años de 
actividad política sostenida y demostraran representar una corriente política definida. Este registro, se transformaba en definitivo si el partido lograba al menos el $1.5 \%$ de los votos, una proporción hasta cierto punto poco exigente.

Y tal vez de lo más significativo (y democrático), fue que se modificó la integración de la Cámara de Diputados con la finalidad de dar márgenes mayores de representación a los partidos minoritarios, estableciéndose un sistema mixto que combinó el principio de representación de mayoría relativa con el de representación proporcional (hasta 100 diputados electos en circunscripciones plurinominales).

De cualquier modo, lejos estuvo de ser la reforma esperada que catapultaría la democracia mexicana. Seguía siendo un sistema de partido hegemónico con un presidente "revolucionario" o, de la gran "familia revolucionaria", con las prerrogativas ya mencionadas (SARTORI, 2000).

\section{La apertura económica democrática}

La post revolución ha concluido. "El momento exacto en que terminó no es, ni puede ser, muy preciso. En mi opinión, una fecha conveniente de conclusión puede ser 1982, el 1 de septiembre para ser exactos" (MEYER, 1986, p. 4). Como en México no funciona(ba) la opinión pública, ni los partidos políticos, ni el parlamento, ni los sindicatos, ni la prensa, ni el radio, ni la televisión, un Presidente de la República podía obrar, y obra(ba), tranquilamente de un modo muy personal y hasta caprichoso (COSÍO, 1974; CASANOVA, 2008).

En 1982, en la bonanza del petróleo, se da la debacle del petróleo; los precios internacionales caen estrepitosamente $y$, los dineros que se habían pedido para "administrar la abundancia", ahora ya no alcanzan para pagarse ni ellos mismos. La deuda se incrementó de 6, 800 millones de dólares en 1976 a 19, mil 107 en 1982. Y el presidente, que habría dicho un par de años antes que "habría que aprender a administrar la abundancia”, para 1982, intentaba por todos los medios defender el peso como un perro, según sus propias palabras, pero no pudo. La crisis lo alcanzó y tuvo que dejar su "encargue" al nuevo presidente, puesto por él, al fin y al cabo, para corregir el rumbo.

Sin embargo, lo que el Presidente no atinaba o quería ver, era que la globalización los había "atrapado" y, que el juego político, no solo el económico, dependía ahora de la economía internacional; quizá por eso dejo en manos el país a su Secretario de Programación y Presupuesto, Miguel de la Madrid Hurtado, que aunque abogado, venía de estudiar en Harvard, su función fue más como economista 
que como legalista. Las presiones internacionales llegaron, México tenía que pagar a los fondistas internacionales y el FMI (Fondo Monetario Internacional) y el BM (Banco Mundial), dictarían las políticas a partir de entonces.

En noviembre de 1982, el gobierno redactó una Carta de Intención para exponerla a la consideración y firma del Fondo Monetario Internacional (FMI). El propósito de esa carta era ajustar la política económica nacional a unos lineamientos previamente aprobados por dicha institución. Adicionalmente solicitó un convenio de facilidad, en el que el FMI apoyaría a México otorgándole créditos urgentes para hacer frente a la crisis económica, con ello, el FMI fungió en carácter de aval para que el país nuevamente fuera susceptible de crédito internacional (CEJA, 2004, p. 10-11).

\section{La democracia económica y los tecnócratas}

Con todo, el rescate neoliberal no pudo contener la crisis.

El primero de los intentos, se desplegó en forma en 1983, sin embargo sus resultados no fueron los esperados. Para 1985, se lanzó el Plan Baker, pero también falló. El último intento Delamadridista aconteció en 1986, y sus resultados tampoco fueron exitosos (RODRÍGUEZ, 2015, p. 3).

Al final, "su administración se caracterizó por la agudización de la crisis económica (CEJA, 2004, p. 14)”.

En 1989, Carlos Salinas de Gortari, el sí economista "graduado en Harvard", habrá de continuar y reafirmar la marcha sin retorno de México a la economía internacional y sus reglas. Para 1990, bajo su mandato, se puso en marcha un nuevo proyecto para la negociación, el Plan Brady (1989), que consistía básicamente en un esquema de recompra, "que permitió por momento dar una solución y (propició la llegada de) nuevos flujos financieros para el crecimiento del país” (GIRÓN, 1995, p. 94).

La fortaleza del capitalismo, asentado ahora en clausulados neoliberales, exigirá la apertura económica, la firma de tratados, la venta de activos nacionales y su privatización $y$, los equilibrios macroeconómicos por encima de la economía doméstica, que les aseguren sus inversiones y les den certeza. Así, México se enfrasca en una ola económica neoliberal sin precedentes. Al término del mandato de Salinas de Gortari, amén del Tratado de Libre Comercio con Estados Unidos y Canadá o TLCAN (Tratado de Libre Comercio de América del Norte), México ha 
comprometido tratados con Costa Rica, Colombia, Venezuela y Bolivia. Ha vendido la Banca, los ferrocarriles y TELMEX (Teléfonos de México); concesionado las carreteras y "entregado" la propiedad ejidal.

No obstante, la otra cara de la moneda es la seguridad legal y democrática para las firmas internacionales que va a arreciar el cambio político iniciado en 1977, en aquella ocasión ciertamente por razones distintas y ahora, por los requerimientos y la exigencia económica internacional (EDEZA, 2001). Así, el órgano electoral se descentraliza y autonomiza en las reformas de 1990 y 1994.

Creando por primera vez un órgano público con personalidad jurídica y patrimonio propios en 1990 y, para 1994, autónomo y ciudadanizado. Con consejeros electos desde la sociedad civil y, aunque en ese ańo vuelve a llegar un presidente del PRI, para el 2000, llegará al primer presidente de oposición, Vicente Fox Quezada, del Partido Acción Nacional (PAN).

\section{La "sociedad democrática"}

No obstante, fue también la sociedad democrática artífice del cambio en México, pero más que por conocimiento por hartazgo dirían algunos, de más de 70 años de autoritarismo y "presión". Lo cierto es que la llegada del candidato de oposición va a traer muchas esperanzas de cambio; cambio que no se dará y que harán regresar nuevamente al PRI, en el 2012, el partido que los vio nacer. Aquí cabrían algunas preguntas: ¿Qué es lo que explica esa desazón? ¿Por qué el pueblo inconforme regresa al opresor y no a otra opción?

Muchas de las personas (mexicanas) que hemos entrevistado señalan que les cuesta trabajo entender asuntos políticos y gubernamentales, cuál consideran que es la principal razón, preguntaban Almond y Verba en 1963: aquellos que se encuentran en el poder y pueden explicar no ayudan a la gente a entender, señalaría el 47,49\% de los mexicanos; contra un 33,28\% que contestó, a la gente no le interesa, ni tampoco trata de entenderlos, muy por debajo por cierto de los demás países de la muestra de democracias "consolidadas". Tal vez ahí cabría parte de la razón.

Habrá que decir que estudios similares a lo largo de los años, mantienen los mismos niveles; en el 2005, por ejemplo, Latinobarómetro señalaba: los países donde hay más conocimiento político (en América Latina), son Argentina, con un 46\% en promedio, seguido de Uruguay y México, con un $45 \%$ cada uno.

Por su parte, las ENCUPs, o encuestas de participación ciudadana de México, registran un 50,5\% en promedio, siendo la última observada en el 2008 y, en el 
último estudio que se levantó, como parte de mi proyecto de investigación de doctorado, tampoco varió mucho, los promedios no rebasaron el $50 \%$ en Índice de Conocimiento Político de los que saben, aunque ciertamente en este caso levantada a nivel de un Estado, Sinaloa (EDEZA, 2014).

\section{La nueva reforma politica}

Es en este contexto y escenario, que se dio la nueva reforma política del 2014; pero los reformadores volvieron a fracasar, creo, habrá que ver. Desde nuestro punto de vista, el Presidente envió un proyecto que contraviene todos los postulados esenciales de los ideales democráticos mexicanos. Erróneos o no, pero que tienen toda una carga emocional no usurpados en los demás intentos. Antes de avanzar en derechos electorales y civiles, como la revocación de mandato, la segunda vuelta electoral, el derecho a la información veraz y objetiva. Discutieron y aprobaron la reelección legislativa; la reelección de alcaldías y diputaciones locales y, el aumento en el umbral para el ingreso o permanencia de los partidos políticos, temas en los cuales la población no concuerda demasiado o al menos, no son prioritarios. Y (en otra de las reformas) su bien emblemático, el petróleo, volverá a ser manoseado.

Sólo el 29,9\% aprobaba la reelección en presidentes municipales y un porcentaje similar, el 28,8\% de diputados, según la última Encuesta Nacional sobre Cultura Política y Prácticas Ciudadanas en México (ENCUP) en el 2012. En tanto que Parametría (2012), una consultoría política de renombre en el país obtenía los siguientes números: $26 \%$ para presidentes municipales, $25 \%$ para gobernadores, $21 \%$ para diputados federales, $20 \%$ para senadores y $21 \%$ para el Presidente de la República. Por otro lado, con todo y que los partidos no eran bien vistos, el 64,26\% los consideraba necesarios (ENCUP, 2012).

Ciertamente, nunca he pensado que la no reelección, sea un rasgo característico de las democracias, antes al contrario. Tampoco, que el capital privado no debiera intervenir en los bienes estratégicos nacionales, sin embargo, lo que si puede y debe ser un rasgo característico de las democracias es que todos la abrasen y valoren como tal; que las instituciones sean aceptadas y que la sociedad se sienta partícipe de ellas. Por encima de una cultura política de participación, se encuentra una cultura cívica de legalidad y legitimación que permee a la sociedad de que se trate (ALMOND y VERBA, 1963; PUTNAM, 1993). No ha sido el caso y, mucho me temo que más que ayudar a la incipiente democracia mexicana, la hará constreñirse y retraerse. 


\section{Contenido de la reforma}

La reforma se inscribió en un acuerdo mayor conocido como Pacto por México, convocado por el Presidente de la República a los líderes de los partidos el 2 de diciembre de 2012 en cinco grandes ejes: 1) Sociedad de derechos y libertades, 2) Crecimiento económico, empleo y competitividad, 3) Seguridad y justicia, 4) Transparencia, rendición de cuentas y combate a la corrupción y, 5) Gobernabilidad democrática.

Así, en la parte política, se propuso y fue aprobada: la reelección legislativa para diputados y senadores, los primeros hasta por 3 veces, para completar 12 años de mandato y, los segundos 1, con lo que también podrán completar 12 años de mandato, ya que su periodo es de 6. Cabe aclarar, que en ninguno de los casos, desde la creación "institucional” del partido en1929, sucedía. Pero además, que esto tiene una carga emocional, tanto, como que fue la proclama revolucionaria de 1910, que evitó en lo sucesivo, las posibilidades de repetir una dictadura. Ciertamente, es solo para la legislatura, pero los que ven más allá, prevén la posibilidad de una dictadura formal, ciertamente también, el partido en el poder lo ha sido de facto, por su entramado legal. Cosa, que no se tocó tampoco. Del mismo modo, habrá reelección para diputados locales y alcaldes, en ambos casos, los congresos locales normarán en la materia.

Por otra parte, se crean fiscalías especiales para los delitos electorales, a partir de 2018; hasta ahora, esta atribución recae en la Procuraduría General de la República. Se crea el Instituto Nacional Electoral (INE), que sustituye al Instituto Federal Electoral (IFE), y tendrá injerencia sobre las elecciones locales, a pedido de las entidades y, el INE, nombrará a los consejeros electorales locales y ya no los congresos estatales.

Se posibilita la nulidad de las elecciones por rebases en los topes de gastos de campańa, pero siempre y cuando ese factor influya en el resultado y su diferencia con el segundo lugar fuera menor al 5\%, con lo que se manda un mensaje claro a permitir la ilegalidad, aunque fuera del 5\%. Hay que decir que la postura de la oposición, concretamente el PAN, era no permitir el rebase así fuera por un peso, pero al final terminó cediendo al concepto de determinancia, esto es, que influyera en los resultados, utilizado por el PRI.

Se amplía el umbral para mantenerse un partido como tal oficialmente del $2 \%$ al 3\% de la votación total emitida. Y aunque en este caso, la gran mayoría de los mexicanos está de acuerdo en la reducción de partidos y legisladores aprueban su 
representación en la cámara. Permaneciendo intocada la proporción de diputados por mayoría y de representación proporcional, lo que seguramente hará, efectivamente reducir el número de partidos, pero también el número de representación.

Por otra parte, se acorta el tiempo entre la elección y la toma de protesta del Presidente electo, del 1 de diciembre al 1 de octubre. $Y$ aunque no hay una fundamentación clara, todo hace suponer querer disminuir las posibilidades de "inestabilidades" y protestas, ya que en las últimas dos elecciones presidenciales la oposición ha argumentado fraudes recurrentes y salido a las calles a protestar.

Se otorga paridad de género, $50 \%$ para hombres y mujeres, de diputados y senadores, legislaturas locales y alcaldías y se establece por primera vez la figura de Gobierno de Coalición. El Presidente podrá recurrir a ello con ratificación del Senado.

Por último, se da autonomía al CONEVAL, que es el Consejo Nacional para la evaluación de la política de desarrollo social, concretamente las políticas asistenciales, y que para muchos representaban el instrumento para el "clientelismo" mexicano. La segunda vuelta electoral, que fue una de las propuestas originales impulsadas por Acción Nacional (PAN), al final no fue contemplada.

Desde nuestro punto de vista, las reforma se da en una nueva acción por legitimar y profundizar el proyecto neoliberal económico (y político) comenzado en 1982. La reforma política, es solo una de las reformas estructurales, que el Presidente de la República envió y aprobó el Congreso en el actual gobierno; junto a ella, está también la Reforma Educativa, que si bien es cierto, plantea en el fondo la eficiencia de la educación mexicana, tiene también una carga modernizadora entre sus objetivos, "recuperar" la rectoría del Estado en el sistema educativo nacional (con todo lo que ello implique), como expresamente lo marca uno de sus objetivos.

Vale decir, que el 26 de febrero de 2013, en pleno proceso de negociación de la reforma, fue detenida y apresada la líder eterna y omnipresente del sindicato magisterial Elba Ester Gordillo, cosa que no está mal, a no ser que "la líder", durante más de 20 años había servido al sistema y ya no apoyaba decididamente al partido en el poder, inclusive, con su venia había creado un nuevo partido, pero enfrentado al régimen abiertamente en el proceso electoral de 2006.

Otra de las reformas cuestionadas, fue la laboral, que si bien también procuraba eficientar la planta productiva y la generación de nuevos empleos, se cuestiona la "permisibilidad" para empleos de medio tiempo o con pagos por hora; la contratación eventual, y la posibilidad de despidos en un plazo que no exceda a los seis meses; con lo que se aduce, según una gran cantidad de estudiosos en la materia, 
no solo no elevará la planta productiva, aún menos la eficientizará y, tenderá sólo a suplantar a la clase trabajadora "formal" por empleados eventuales que no generen derechos laborales, con lo que el beneficio sería más para el empresario que para el trabajador.

En el mismo tenor, se inscribe la reforma fiscal, que en un intento de ser más recaudadora, generalizó el IVA (Impuesto al Valor Agregado) o impuesto al consumo, a alimentos (de consumo básico) y medicinas, que había sido uno de los "logros" populares, sin tocar el ISR (o impuesto sobre la renta o ingreso) o, reformar los mecanismos para el control de la evasión fiscal, que acontece en gran parte de la clase empresarial.

Pero sin duda la más cuestionada y aún polémica, es la reforma energética, que por primera vez y después de la nacionalización del petróleo en 1938 como un bien público y estratégico del Estado Mexicano, permitirá la inversión privada en su extracción y distribución. Esto es simbólico, porque además de la Revolución, me atrevo a decir, fue (y ha sido) "la Nacionalización del Petróleo" (ni siquiera el petróleo mismo), el momento de mayor unidad e "identidad" de los mexicanos. Casi como la consumación misma de la Revolución.

\section{Conclusiones}

Irónicamente, tal vez estemos ante el último presidente de derecha en la nación mexicana. Dependerá, de si el presidente es capaz de "combinar" los postulados económicos neoliberales con los postulados políticos de su partido o, si querrá de una vez por todas seguir los cánones de la democracia aún con esta reforma un tanto contrahecha; de si preferirá seguir posponiendo la historia.

La economía importa, pero no es suficiente, se trata de entregar igualdad de derechos políticos y sociales. Con una población (cada vez más) desideologizada, decepcionada de la política, con bajos niveles de confianza y ciudadanos empoderados, la demanda de más y mejor democracia y la demanda de más y mejor sociedad están en las calles de la región, señala Latinobarómetro, en su reporte 1995-2015.

¿Las sociedades que no son liberales, sino tradicionales y culturalmente conservadoras, tienen las condiciones para que funcione una democracia liberal?, pregunta.

América Latina se diferencia del resto de las regiones del mundo en la medida que a pesar de crecer económicamente, conseguir bienes de consumo, construir su clase media, no abandona sus valores tradicionales. El valor de la libertad está 
limitado por las costumbres. Hay demanda de democracia, aumenta el valor de la igualdad, pero el valor de la libertad no crece. La democracia es más que todo una aspiración para los ciudadanos de la región, algo que no sucede aún, pero que se espera que suceda. (Más) Esa demanda de democracia va aparejada con bajos niveles de educación, y bajos niveles de información. La mezcla es compleja, porque no solo está llena de prejuicios, sino también está llena de historia (LATINOBARÓMETRO, 2015).

Es decir, pareciera que la cultura histórica del pueblo mexicano, está aún de su parte, tan es así, que regresaron a elegirlos en el 2012. Pero no sé por cuánto tiempo.

La misma exigencia internacional por el cambio económico y político, en ese orden, irónicamente terminará por revertir la secuencia y estaremos en los próximos años, ante un presidente surgido de su reforma política, pero ya no mandado por la reforma económica, sino como un elemento político de una sociedad que habrá de exigir su camino. "La democracia es inercial", diría Marcelo Baquero (2006).

Por cierto, el estudio de Latinobarómetro (2015) también señala que la población en América Latina tiene altas expectativas y crecientes grados de empoderamiento y opiniones cada vez más críticas.

El mundo ha vuelto a cambiar y considero que los mexicanos cambiarán con él a pesar del "texto". La globalización económica ha dado paso a la globalización de la información y, el internet y las "redes sociales", podrán en un futuro hacer la tarea que se han negado, creo. Un elemento crucial habrá de ser la globalización de la información, el internet y las redes sociales.

Entre 2010 y 2015 ha aumentado en 15 puntos porcentuales los latinoamericanos que señalan han usado el internet, $54 \%$ con un $46 \%$ que sigue diciendo que nunca lo ha usado. Ciertamente, la población de la región tiene opiniones diversas sobre lo que implican las redes sociales como forma de participación política. Un $27 \%$ señala que sí sirven, mientras que el $22 \%$ dice que crean la ilusión de que se participa, un 23\% no responde, tan sólo un 30\% de los ciudadanos respondió determinantemente que no servía.

En México, éste indicador de utilidad es de $27 \%$, lo que ciertamente señala de algún modo una baja percepción de utilidad, no obstante, la otra cara de la moneda, es que tan sólo un $12 \%$ de los ciudadanos mexicanos respondió determinantemente que no servía. 
Lo que preocupa es saber si se irá por el camino correcto o, como los fundadores y reformadores, se habrá de fracasar nuevamente. Por eso es importante ordenar la información.

Manuel Ángel Rodríguez Edeza é Doutor em Ciências Sociais
pela Universidad Autónoma de Sinaloa. Professor da Universidade
de Occidente e, atualmente, Professor Visitante da Universidade
Federal do Rio Grande do
maredezasinaloa@hotmail.com.

\section{Bibliografia}

ALMOND, Gabriel; VERBA, Sidney. The civic culture. New Yersey, Princeton University Press. 1963.

BAQUERO, Marcello; CREMONESE, Dejalma. O que o capital social pode fazer na construção de uma sociedade participativa. In: Capital Social: teoria e prática.UNIJUI - Universidade Regional do Noroeste do Estado do Rio Grande do Sul. 2006.

CARPIZO, Jorge. El presidencialismo mexicano. México. 1978.

CASANOVA, Francisco Álvarez.De la presidencia imperial al presidencialismo acotado. México, UNAM. $2008 . \quad$ Disponible en: http://www.journals.unam.mx/index.php/multidisciplina/article/view/27668> Acceso en: 4 mar. 2017.

CEJA Concepción Mena. La política social mexicana de cara a la pobreza. Núm. 176. Vol. VIII. Barcelona, Revista Electrónica de Geografía y Ciencias Sociales. 2004.

COSÍO, Daniel Villegas. El sistema político mexicano. México, Cuadernos de Joaquín Mortiz. 1973.

COSÍO, Daniel Villegas.El estilo personal de gobernar. México, Cuadernos de Joaquín Mortiz. 1974.

CRESPO, José Antonio. Contra la historia oficial. México, Debate.2009.

EDEZA, Manuel Ángel. La crisis del PRI. In: Trabajo-resumen: introducción a la estadística para las ciencias sociales. México, UAM-I. 2001.

EDEZA, Manuel Ángel. La relación entre el conocimiento político y la pluralidad electoral en el Estado de Sinaloa: 1989-2010. Tesis de doctorado, México, Universidad Autónoma de Sinaloa. 2014.

ENCUP. Disponible en: <www.encup.gob.mx/> Acesso en: 13 fev. 2017.

GARCÍA, Bernardo M. "La época colonial hasta 1760". In: Nueva Historia Minima de México. México, El Colegio de México. 2004.

GIRÓN, Alicia. Renegociación tras renegociación. In: Fin de Siglo y Deuda Externa: Historia Sin Fin, Argentina, Brasil y México. México, IIE.1995. 
GONZÁLEZ, Rodrigo Stumpf. Cultura Política y Calidad de la democracia en Brasil y España: Impacto de los Legados del Autoritarismo.Plan de trabajo para estancia postdoctoral en Universidad Autónoma de Madrid. Brasil, UFRGS. 2015.

KRAUZE, Enrique. Siglo de caudillos. México, Tusquets. 1994.

KRAUZE, Enrique.Biografía del poder. México, Tusquets. 1997.

KRAUZE, Enrique. La presidencia imperial. México, Tusquets. 1997.

LATINOBARÓMETRO, Disponible en: <www.latinobarometro.org/> Accesso en: 11 de jan. 2017.

MEYER, Lorenzo. Los tiempos de nuestra historia. México,, Estudios de filosofía, historia y letras. 1986.

PARAMETRIA. Disponible en: <www.parametria.com.mx/> Accesso en: 23 fev. 2017.

PAZ, Octavio. Posdata, Siglo XXI, México, 1970.

PUTNAM, Robert D. Making democracy work. Civic traditions in modern Italy, New Yersey, Princeton University Press. 1993.

RAMIREZ, Carlos. Indicador político. México, Periódico El universal. 2015.

RODRÍGUEZ, Hernández. Reporte de Investigación 119. México, 2015.

Disponible en: <htpp//cam.economia.unam.mx/reporte-de-investigacion-119-la-deuda-que-todos-losmexicanos-debemos-de-pagar-entre-la-historica-irresponsabilidad-eldespilfarro-y-la-corrupciongubernamental-y-la-avaricia-de-los-pres> Accesso en: 13 de fev. 2017

SARTORI, Giovanni. Partidos y sistemas de partidos. Madrid, Alianza Editorial. 2000. 